\title{
Circulating angiogenic factors and their association with birth outcomes in preeclampsia
}

\author{
Asmita V Kulkarni ${ }^{1}$, Savita S Mehendale ${ }^{2}$, Hemlata R Yadav ${ }^{1}$, Anitha S Kilari ${ }^{1}$, Vaishali S Taralekar ${ }^{2}$ \\ and Sadhana R Joshi ${ }^{1}$
}

This study was designed to test the hypothesis that altered angiogenic factors together with increased oxidative stress and reduced docosahexaenoic acid (DHA) levels may be associated with altered birth outcome parameters. To test this hypothesis, levels of plasma vascular endothelial growth factor (VEGF), placental growth factor (PIGF), soluble fms-like tyrosine kinase-1 (sFIt-1), the oxidative stress marker malondialdehyde (MDA) and fatty acids were estimated in women with preeclampsia and their cord samples and compared with those in normotensive women. The association of these parameters with birth outcome was also examined. Our results show that in preeclamptic women, maternal plasma VEGF and PIGF levels were lower, whereas sFIt-1 levels were higher $(\boldsymbol{P}<0.05$ for all) than in normotensive women. In contrast, cord plasma VEGF levels were higher $(P<0.05)$ in preeclamptic women, whereas there was no difference in sFlt-1 levels. Plasma DHA levels in both the mother and cord were lower $(P<0.05)$ in the preeclamptic group compared with normotensive women. Maternal plasma sFlt-1 levels were positively ( $n=23, r=0.415, P=0.039$ ) associated with MDA concentrations in preeclamptic women. Maternal plasma sFlt-1 levels showed a strong negative association with baby weight $(n=37, r=-0.547, P=0.001)$, head circumference $(n=37$, $r=-0.472, P=0.005)$ and baby chest circumference $(n=37, r=-0.375, P=0.032)$ in the preeclamptic group. Cord plasma sFIt-1 concentrations were negatively associated with cord plasma DHA concentrations $(n=28, r=-0.552, P=0.004)$. This study suggests that dysregulation of angiogenic factors may be associated with maternal oxidative stress. Increased oxidative stress may reduce cord DHA levels and increase sFlt-1 levels, leading to poor birth outcomes in preeclampsia.

Hypertension Research (2010) 33, 561-567; doi:10.1038/hr.2010.31; published online 12 March 2010

Keywords: birth outcome; DHA; oxidative stress; preeclampsia; sFIt-1

\section{INTRODUCTION}

Preeclampsia is a systemic syndrome of pregnancy that originates in the placenta. In this condition, the placenta is ischemic and hypoperfused and is characterized by widespread maternal endothelial dysfunction. ${ }^{1}$ The syndrome, which affects $5-7 \%$ of pregnancies, is associated with significant fetal/neonatal and maternal morbidity and mortality. ${ }^{2}$ Despite extensive research on preeclampsia, its molecular pathogenesis is still largely unknown. ${ }^{3}$ It is now generally accepted that preeclampsia starts with inadequate cytotrophoblast invasion and leads to widespread maternal endothelial dysfunction. ${ }^{4}$ Recent studies suggest that dysregulation of angiogenic factors and their soluble fmslike tyrosine kinase- 1 receptors (sFlt-1) has an important role in the pathogenesis of preeclampsia, but the results are inconsistent. Although some studies report lower plasma vascular endothelial growth factor (VEGF) levels $s^{5}$ in preeclamptic women compared with normotensive women, ${ }^{6-9}$ other studies report higher levels in preeclamptic women, ${ }^{10,11}$ and some found no difference between the two groups. ${ }^{5}$ Placental growth factor (PlGF) is a placental protein that potentiates the effect of VEGF. ${ }^{12}$ sFlt-1, also known as soluble vascular endothelial growth factor receptor-1, is an anti-angiogenic protein that is increased before the onset of the clinical disease in women with preeclampsia and is correlated with the severity and time to onset of the disease. ${ }^{6,13,14}$

sFlt-1, which is released into maternal circulation, disrupts the maternal endothelium, leading to hypertension, proteinuria and other systemic manifestations of preeclampsia. Most of the published studies have examined the levels of all the angiogenic factors in a small number of mother and cord samples. ${ }^{9,15}$ Furthermore, their associations with birth outcome are very rarely examined. ${ }^{16}$ Very little is known about the mechanisms by which factors such as sFlt-1 may contribute to the preeclamptic syndrome. ${ }^{17}$ It is suggested that sFlt-1 binds to both VEGF and PlGF, ${ }^{18,19}$ reducing their free levels in the blood by working as a soluble antagonist of both factors. ${ }^{20}$ It is believed that hypoxia in preeclampsia leads to increased production of sFlt- 1 in placental trophoblasts ${ }^{15,21}$ and is suggested to be the major source of circulating sFlt- $1 .{ }^{22}$ Others believe that hypoxia may not be

${ }^{1}$ Department of Nutritional Medicine, Interactive Research School for Health Affairs, Bharati Vidyapeeth University, Pune, India and ${ }^{2}$ Department of Obstetrics and Gynecology, Bharati Medical College and Hospital, Bharati Vidyapeeth University, Pune, India

Correspondence: Dr SR Joshi, Department of Nutritional Medicine, Interactive Research School for Health Affairs, Bharati Vidyapeeth University, Pune 411043, India E-mail: srjoshi62@gmail.com

Received 13 November 2009; revised and accepted 1 February 2010; published online 12 March 2010 
the only or main stimulus to release sFlt-1 and emphasize the role of inflammatory mechanisms. ${ }^{23}$ It is also believed that other factors, such as alterations in the renin-angiotensin-aldosterone axis, immune maladaptation, excessive shedding of trophoblast debris and oxidative stress, contribute to the pathogenesis of abnormal placentation. $^{24}$

A recent study in rats suggests that chronic infusion of plasma sFlt-1 causes hypertension associated with increased oxidative stress and endothelial dysfunction. ${ }^{25}$ Our previous studies in preeclamptic women have shown increased oxidative stress, leading to altered essential polyunsaturated fatty acid levels, especially docosahexaenoic acid (DHA), one of the factors responsible for preeclampsia. ${ }^{26} \mathrm{We}$ hypothesize that altered angiogenic factors together with increased oxidative stress and reduced DHA levels may be associated with altered birth outcome parameters.

This study therefore simultaneously examines (i) the levels of angiogenic factors, such as VEGF, PlGF and sFlt-1, in both maternal and cord samples and (ii) the associations of these factors with (a) malondialdehyde (MDA) concentrations (an oxidative stress marker), (b) DHA and (c) birth outcome in preeclamptic and normotensive women who were matched for gestation, age, body mass index and socioeconomic status.

\section{METHODS}

This study was conducted at the Department of Obstetrics and Gynecology, Bharati Hospital, Pune, from 2007 to 2009. The study was approved by the Institutional Ethical Committee, and written informed consent was obtained from each subject. A total of 117 pregnant women (59 normotensive and 58 preeclamptic women with singleton pregnancy) were recruited at term. Women were excluded from the study if there was evidence of other pregnancy complications, such as multiple gestation, chronic hypertension, type 1 or type 2 diabetes mellitus, seizure disorder and renal or liver disease. Pregnant women with alcohol or drug abuse were also excluded from the study. The normotensive group consisted of pregnant women with no medical or obstetrical complications.

Preeclampsia was defined by systolic and diastolic blood pressures greater than 140 and $90 \mathrm{~mm} \mathrm{Hg}$, respectively, with the presence of proteinuria ( $>1+$ or $300 \mathrm{mg}$ per $24 \mathrm{~h}$ ) on a dipstick test. Edema was present in some cases. Blood pressure was measured in the left arm with a mercury sphygmomanometer. Preeclampsia was confirmed by repeated recording of the blood pressure with an interval of $6 \mathrm{~h}$ at the time of diagnosis. Blood pressure was recorded frequently, starting at enrollment and at every follow-up visit, which occurred approximately once a month until delivery in both groups. In preeclamptic women, blood pressure was monitored frequently in the last week of delivery; the monitoring period ranged from $24 \mathrm{~h}$ to the full 7 days. In normotensive women, blood pressure was consistent with those previously obtained during the gestational period. The blood pressure in some preeclamptic women was lower as a result of antihypertensive drugs but was still higher than that of the normotensive women. The data given here are the blood pressures at the time of delivery, that is, just before going to the labor room, to ensure that a similar time point was used for both groups to rule out the effect of stress due to labor on blood pressure.

Gestational age was based on the day of the last menstrual period and then confirmed by ultrasound. Both preeclamptic and normotensive women were from a lower socioeconomic group and had similar levels of education and lifestyle. None of the women in either group smoked.

\section{Sample collection and processing}

Ten milliliters of maternal venous blood was collected before delivery in EDTA vials. In addition, $10 \mathrm{ml}$ of blood was collected from the umbilical cord just after delivery on a subsample. The blood was immediately layered on Histopaque (Sigma-Aldrich, St Louis, MO, USA) and centrifuged at 1800 r.p.m. for $35 \mathrm{~min}$ to separate the plasma and erythrocytes. The erythrocyte fraction was washed 3 times with normal saline. Then, the plasma and erythrocyte aliquots were stored at $-80{ }^{\circ} \mathrm{C}$ until further analysis. Birth weight, birth height, and head and chest circumference were recorded by standard techniques within half an hour after birth.

\section{Dietary assessments}

A food frequency questionnaire was used to estimate the frequency of intake of foods rich in $\omega-3$ fatty acids. These foods were identified using 'Nutritive Values of Indian Foods. ${ }^{27}$ The questionnaire consisted of 17 food groups, and several foods (approximately 10) were listed under each of the food groups. The frequency of intake of each food group was recorded on an eight-point scale from 'never' to 'thrice daily.' Monthly scores were calculated for each food item. For example, an item consumed once a week had a score of 4 , whereas one consumed daily had a score of 30 .

\section{VEGF, PIGF and sFlt-1 levels from maternal and cord plasma samples}

Plasma-free VEGF, PlGF and plasma sFlt-1 levels were measured from both maternal and cord samples using commercial enzyme-linked immunosorbent assay (ELISA) kits (R\&D Systems, Minneapolis, MN, USA). The detection limit (sensitivity) of the assay was $9 \mathrm{pg} \mathrm{ml}^{-1}$ for VEGF, $7 \mathrm{pg} \mathrm{ml}^{-1}$ for PlGF and $13.5 \mathrm{pg} \mathrm{ml}^{-1}$ for sFlt-1. All assays were carried out by personnel who were blinded to the study. All ELISA assays were standardized to have less than $5 \%$ coefficients of variance for both intra- and inter-assay measurements.

\section{Oxidative stress marker (MDA)}

MDA levels were estimated from maternal plasma using a kit (Oxis MDA-586, Oxis International, Foster City, CA, USA). Briefly, thiobarbituric acid reacts with MDA to form a pink color, and the absorbance was measured at $586 \mathrm{~nm}$. Tetramethoxypropane is used as a standard. MDA concentration is expressed as $\mu \mathrm{mol} \mathrm{ml}^{-1}$.

\section{Fatty acid estimation from maternal and cord plasma}

The procedure for fatty acid analysis used in our study was revised from the original method of Manku et al., ${ }^{28}$ and the method we used in previous studies. ${ }^{26,29,30}$ Briefly, transesterification of the phospholipid fraction was performed using hydrochloric acid-methanol. Methyl esters were separated using a Perkin Elmer gas chromatograph (SP 2330, $30 \mathrm{~m}$ capillary Supelco column, Perkin Elmer, Shelton, CT, USA). Helium was used as a carrier gas at $1 \mathrm{ml} \mathrm{min}^{-1}$. The oven temperature was maintained at $150^{\circ} \mathrm{C}$ for $10 \mathrm{~min}$, programmed to rise from 150 to $220^{\circ} \mathrm{C}$ at $10^{\circ} \mathrm{Cmin}^{-1}$ and at $220^{\circ} \mathrm{C}$ for $10 \mathrm{~min}$. The detector temperature was $275^{\circ} \mathrm{C}$ and the injector temperature was $240^{\circ} \mathrm{C}$. Retention times and peak areas were automatically computed. Peaks were identified by comparison with standard fatty acid methyl esters (Sigma-Aldrich). Fatty acids were expressed as g per $100 \mathrm{~g}$ fatty acid. The total $\omega$-3 fatty acids included $\alpha$ linolenic acid, eicosapentaenoic acid and DHA.

\section{Statistical analysis}

Values are reported as mean \pm s.d. The data were analyzed using the SPSS/PC+ package (Version 11.0, Chicago, IL, USA). Mean values of the estimates of various parameters for maternal and cord samples were compared using unadjusted independent sample $t$-tests to identify statistically significant differences $(P<0.05)$. Skewed variables were transformed to normality using the transformation log to base 10 (sFlt-1). The correlation between variables was studied using Pearson's correlation analysis after adjusting for gestation, age and body mass index.

\section{RESULTS}

Table 1 shows the demographic characteristics of mothers and their neonates. The mean systolic and diastolic blood pressures in the preeclamptic group were significantly higher than in the control group. body mass index, weight and height did not differ between the groups. The frequency of consumption of $\omega$-3-rich foods was similar in both groups. Birth outcome was poor in the preeclamptic group compared with the normotensive group, which could also be attributed to the shorter gestational period of the preeclamptic women. 
Table 1 Maternal and neonatal characteristics of normotensive and preeclamptic women

\begin{tabular}{|c|c|c|}
\hline & \multicolumn{2}{|c|}{ Mean \pm s.d. } \\
\hline & $\begin{array}{l}\text { Normotensive } \\
\quad(\mathrm{n}=59)\end{array}$ & $\begin{array}{l}\text { Preeclamptic } \\
\qquad(\mathrm{n}=58)\end{array}$ \\
\hline \multicolumn{3}{|l|}{ Maternal characteristics } \\
\hline Age (year) & $22.4 \pm 3.0$ & $23.41 \pm 4.0$ \\
\hline Body mass index $\left(\mathrm{kg} \mathrm{m}^{-2}\right)$ & $22.2 \pm 2.9$ & $23.3 \pm 4.4^{*}$ \\
\hline Weight (kg) & $51.09 \pm 6.54$ & $54.04 \pm 10.03$ \\
\hline Height (cm) & $151.81 \pm 5.35$ & $152.79 \pm 6.01$ \\
\hline Income (USD per month) & $102.5 \pm 72.9$ & $118.4 \pm 84.4$ \\
\hline Education (grade) & $10 \pm 3$ & $10 \pm 3$ \\
\hline Gestation (weeks) & $39 \pm 1$ & $38 \pm 1^{* *}$ \\
\hline Systolic blood pressure (mm Hg) & $125 \pm 7$ & $147 \pm 13^{* *}$ \\
\hline Diastolic blood pressure (mm Hg) & $80 \pm 6$ & $97 \pm 9.2^{* *}$ \\
\hline \multicolumn{3}{|l|}{ Neonatal characteristics } \\
\hline Baby weight (kg) & $2.9 \pm 0.2$ & $2.7 \pm 0.4^{* *}$ \\
\hline Baby length (cm) & $48.6 \pm 2$ & $48.0 \pm 2.7$ \\
\hline Head circumference $(\mathrm{cm})$ & $34.2 \pm 1.2$ & $33.5 \pm 1.7^{* *}$ \\
\hline Chest circumference $(\mathrm{cm})$ & $32.6 \pm 1.2$ & $31.7 \pm 1.8^{* *}$ \\
\hline
\end{tabular}

${ }^{*} P<0.05 ;{ }^{* *} P<0.01$.

\section{Maternal and cord plasma VEGF, PIGF and sFlt-1 levels}

Figure 1 shows the circulating VEGF and sFlt-1 levels in maternal and cord plasma and the PlGF levels in maternal plasma. In preeclamptic women, plasma VEGF levels were significantly lower than in normotensive women. In contrast, cord plasma VEGF levels were significantly higher in the preeclamptic group than in the normotensive group. Plasma PlGF levels were significantly lower in preeclamptic women than in normotensive women, whereas the cord plasma PlGF levels were below the detection limit of the kit used in both the groups. In the preeclamptic group, maternal plasma showed increased sFlt-1 levels compared with the normotensive group. However, there was no difference in cord sFlt-1 levels between the groups. There was a significant increase in the plasma sFlt-1/PIGF ratio in the preeclamptic group, but not in the normotensive group.

\section{Associations between maternal plasma MDA levels and plasma VEGF, PIGF and sFlt-1 levels}

Maternal plasma MDA levels were significantly higher in preeclamptic women $\left(10.72 \pm 2.20 \mu \mathrm{mol} \mathrm{ml}^{-1}, \quad n=32\right.$, ) than in normotensive women $\left(9.53 \pm 2.45 \mu \mathrm{mol} \mathrm{ml}^{-1}, n=32\right)(P=0.029)$ and were significantly positively associated with maternal plasma sFlt-1 levels $(n=32$, $r=0.415, P=0.039$ ) only in the preeclampsia group. There was no association of maternal MDA levels with maternal VEGF or PlGF levels.

\section{Maternal and cord fatty acid levels}

There was a significant reduction $(P<0.05)$ in plasma DHA levels in mothers in the preeclamptic group $(n=56,1.23 \pm 0.74 \mathrm{~g}$ per $100 \mathrm{~g}$ fatty acids) compared with the normotensive group $(n=55,1.48 \pm 0.62 \mathrm{~g}$ per $100 \mathrm{~g}$ fatty acids), which we previously reported. ${ }^{26,28} \mathrm{~A}$ similar reduction in plasma DHA levels was also seen in the cord $(2.08 \pm 0.82 \mathrm{~g}$ per $100 \mathrm{~g}$ fatty acids, $n=44)$ in the preeclamptic group compared with the normotensive group $(2.52 \pm 0.99 \mathrm{~g}$ per $100 \mathrm{~g}$ fatty acids, $n=48)$.
Associations between maternal and cord angiogenic factors

There was a positive association between maternal and cord VEGF levels $(n=40, r=0.541, P=0.001$ ) only in the normotensive group. However, there was no association between maternal and cord sFlt-1 levels in both the normotensive and preeclamptic groups.

Associations between plasma polyunsaturated fatty acids and plasma VEGF, PLGF and sFlt-1 levels in the mother and cord There was no association between maternal plasma polyunsaturated fatty acids and plasma VEGF, PlGF and sFlt-1 levels in the mother or cord in the normotensive and preeclamptic groups. In contrast, cord plasma sFlt-1 levels were negatively associated with cord plasma DHA $(n=34, r=-0.552, P=0.004)$ and $\omega-3$ fatty acid $(n=28, r=-0.498$, $P=0.011)$ concentrations (Figure 2).

\section{Associations between maternal plasma VEGF, PIGF and sFlt-1 with birth outcome}

Maternal VEGF levels did not show any association with birth outcome in the preeclamptic or normotensive group, whereas maternal PlGF levels were negatively associated with baby length only in the preeclamptic group (Table 2). In contrast, maternal plasma sFlt-1 levels showed a strong negative association with baby weight, head circumference and chest circumference only in the preeclamptic group. The maternal sFlt-1/PlGF ratio showed a strong negative association with baby head circumference in the preeclamptic group. There were no associations with cord VEGF in the normotensive and preeclamptic groups. However, cord sFlt-1 only showed a negative association with baby weight, head and chest circumference in the normotensive group (Table 3 ).

\section{DISCUSSION}

This study reveals for the first time several novel and interesting findings in normotensive and preeclamptic women who were matched for age, gestation and socioeconomic status: (1) decreased maternal VEGF and PlGF levels but increased sFlt-1 levels in preeclamptic women compared with normotensive women; (2) increased VEGF levels in cord samples in preeclampsia; (3) increased maternal plasma sFlt-1 levels that were positively associated with maternal MDA concentrations; (4) increased maternal plasma sFlt-1 levels that were inversely associated with adverse birth outcomes in preeclamptic women and (5) increased cord plasma sFlt-1 levels that were negatively associated with cord plasma DHA concentrations.

In this study, free VEGF and PlGF levels in preeclamptic women were significantly reduced, whereas sFlt-1 levels were significantly increased, compared with normotensive women, suggesting that dysregulation of these angiogenic factors may explain the defective uteroplacental vascularization that characterizes preeclampsia. A similar decrease in free maternal VEGF levels has also been reported by others. ${ }^{8,31}$ It has been suggested that VEGF is responsible for the adequate perfusion of the feto-placental unit, normal fetal oxygenation, nutrition and appropriate intrauterine fetal growth; ${ }^{9}$ the reduced VEGF levels observed in our study are similar to those found in other studies. ${ }^{6-9}$

Reduced PlGF levels have been suggested to be a result of inadequate placental production, ${ }^{12}$ which has been previously reported. ${ }^{7,32}$ Qazi et al. ${ }^{33}$ have examined the circulating levels of VEGF and sFlt-1 and suggested that decreased VEGF levels resulting from elevated sFlt1 might be a potential cause of the pathogenesis of preeclampsia.

Several studies carried out in Western countries have consistently reported increased levels of plasma sFlt-1 $1^{8,15,34-41}$ in mothers with preeclampsia compared with normotensive women. Our results 

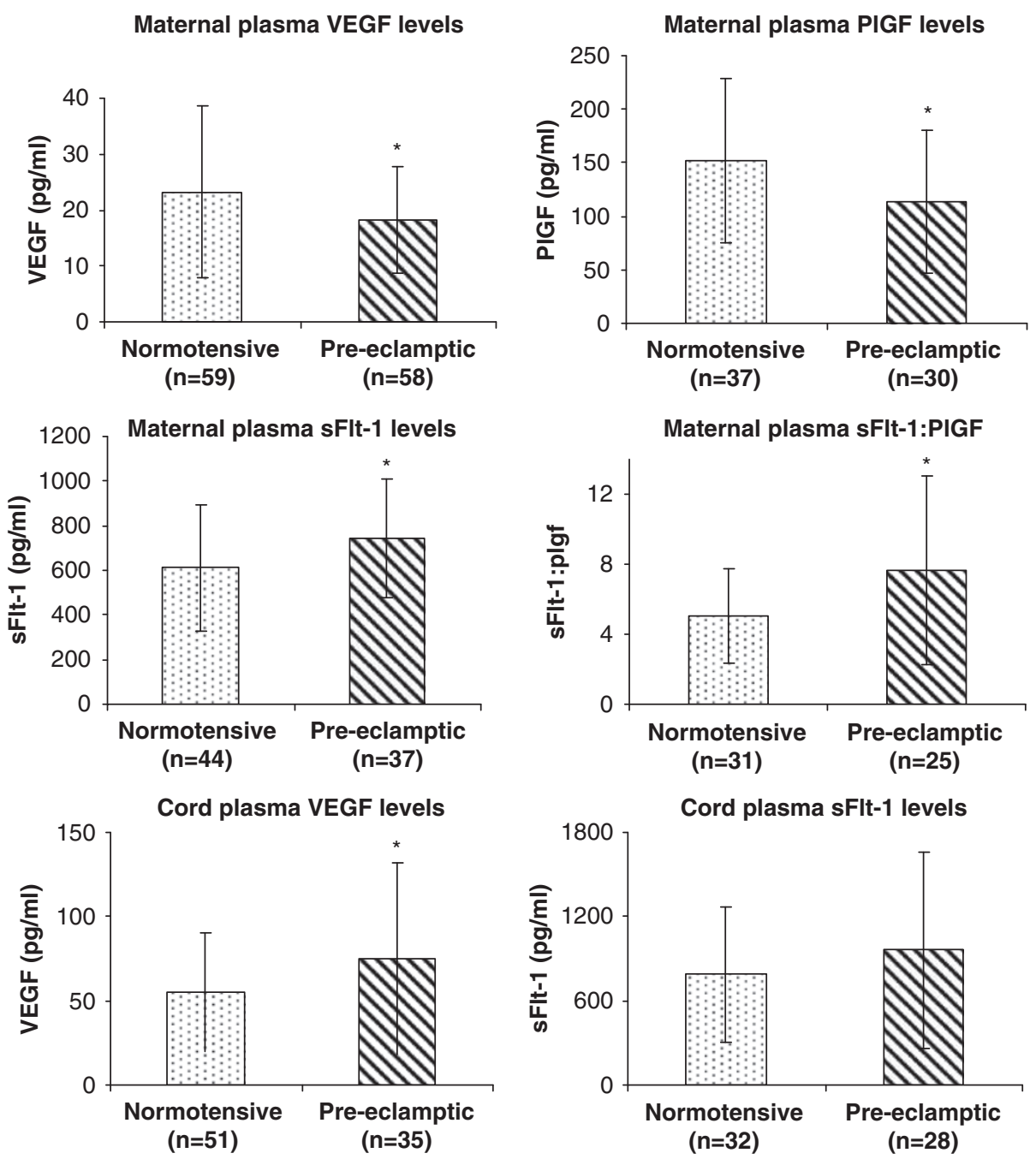

Figure 1 Comparison of maternal and cord angiogenic factors in normotensive and preeclamptic groups, ${ }^{*} P<0.05$; VEGF, vascular endothelial growth factor; PIGF, placental growth factor; sFlt-1, soluble fms similar to tyrosine kinase receptor-1.

suggest that Indian women with preeclampsia also have a similar increase in plasma sFlt-1 levels. sFlt-1, a splice variant of the VEGF receptor Flt-1, which lacks the transmembrane and cytoplasmic domains, is made in large amounts by the preeclamptic placenta and is released into maternal circulation. ${ }^{19,42}$ It is believed to exert its biological activity by binding to and thereby neutralizing VEGF and PlGF. ${ }^{18}$ The higher relative concentrations of sFlt-1 are believed to trigger vascular endothelial cell injury in the liver, kidney, brain and the placenta itself. ${ }^{20}$ However, the mechanisms by which these factors, especially sFlt-1, may exert their effects have remained unclear. ${ }^{25}$

In our study, there was a significant increase in the sFlt-1/PlGF ratio in preeclamptic women at the end of pregnancy, and it would be worthwhile to examine the levels of these factors in early pregnancy. Changes in either sFlt-1 itself or together with PlGF may serve as possible predictors of preeclampsia before the manifestation of overt symptoms (for example, hypertension, proteinuria) as recently suggested. ${ }^{5,12,36,43}$ Furthermore, the sFlt-1/PIGF ratio in early-onset preeclampsia has been reported to be higher than that in late-onset preeclampsia. ${ }^{44}$ Reports from a recent animal study indicate that the injection of exogenous sFlt-1 in pregnancy induced oxidative stress and hypertension. ${ }^{25}$ It is therefore possible that our findings of altered levels of sFlt-1 and its association with fetal outcome may have potential as predictors of preeclampsia.

The cord VEGF levels in this study were increased in the preeclamptic group and support previous findings ${ }^{35,45,46}$ that elevated umbilical cord serum VEGF levels might be correlated with the clinical development of preeclampsia. However, reduced cord plasma VEGF levels in preeclampsia are also reported..$^{31,46}$ Vascular endothelial growth factor (VEGF) is a secreted vascular mitogen that is purportedly specific to endothelial cells and has an important regulatory role in vascular growth in several organ systems during development. ${ }^{47} \mathrm{It}$ has also been suggested that VEGF may be involved in the regulation of amniotic fluid volume and composition. ${ }^{48}$ VEGF may have additional actions that point to a neurotrophic role in nervous tissue. When VEGF was applied to fetal ventral mesencephalic explants, a substantial increase in neuritic outgrowth and enhanced survival of dopaminergic neurons were found compared with nontreated explants. ${ }^{49}$ It is also known that babies born to preeclamptic mothers will be at increased risk for various metabolic syndromes, such as cardiovascular disease, later in life. ${ }^{50}$ In this study, cord plasma PlGF levels were below the detection limit in both groups, and similar findings were previously reported. ${ }^{51,15}$ In our study, sFlt-1 levels in 


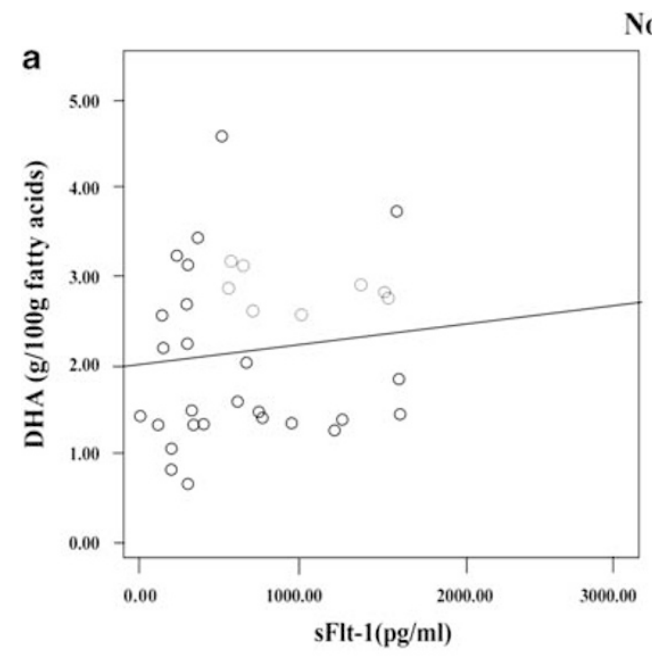

Normotensive
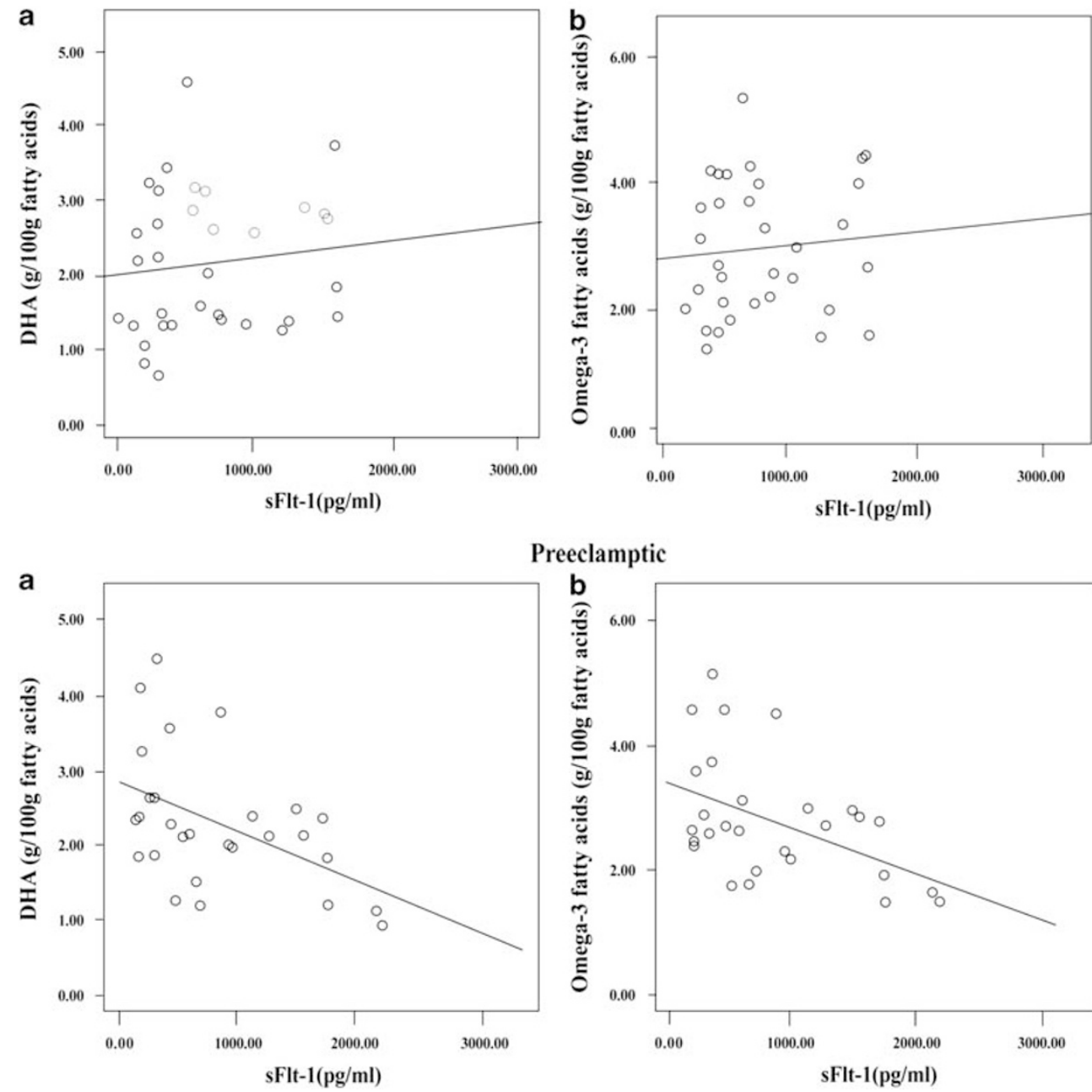

Preeclamptic

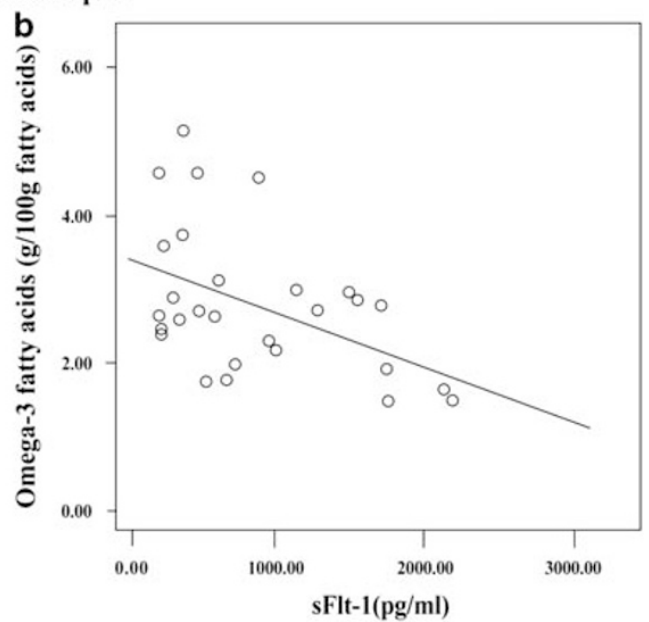

Figure 2 (a) Associations between cord plasma sFlt-1 and docosahexaenoic acid (DHA): normotensive group, $n=34, r=0.114, P=0.541$; Preeclamptic group $n=28, r=-0.552, P=0.004$. (b) Association between cord plasma sFlt- 1 and $\omega$-3 fatty acids; normotensive group, $n=34, r=0.072, P=0.700 ;$ Preeclamptic group, $n=28, r=-0.498, P=0.011$.

cord plasma were increased, although they were not significant in preeclampsia, consistent with earlier reports. ${ }^{51}$ Some studies have also shown that infants with maternal preeclampsia had higher cord blood sFlt-1 but lower PlGF and VEGF levels., $9,45,46$

Levels of angiogenic factors may be regulated differently in the maternal and cord plasma of preeclamptic women. The higher levels of VEGF in cord plasma may indicate increased expression in response to hypoxia to stimulate normal angiogenesis in the fetus. The maternal plasma levels represent free circulating VEGF. As there is no increased demand for angiogenesis in the mother peripherally, maternal levels are low. ${ }^{52,53}$ Slightly reduced VEGF levels in plasma may also be partly due to the complex with circulating sFlt- 1 that is released from the placenta. The polarized secretion of sFlt-1 into the maternal compartment but not into the fetal side enables angiogenesis, which is essential for normal development to take place in the materno-fetal unit and is thought to protect the mother against excessive angiogenic stimulation. ${ }^{53}$

In this study, maternal MDA levels showed an association with sFlt-1, which by itself has been shown to induce oxidative stress. A recent study in rats has shown that the chronic infusion of plasma sFlt-1 causes hypertension associated with increased oxidative stress and endothelial dysfunction, although the mechanism remains unknown. ${ }^{25}$ Some studies have indicated that VEGF is important in controlling oxidative stress in the cell and contributing to the maintenance of vascular tone through nitric oxide production. ${ }^{54-56}$ Previously, we reported increased oxidative stress in umbilical cord blood samples in preeclampsia. ${ }^{26}$ In this study, we also found a negative association between cord sFlt-1 levels and $\omega$-3 fatty acids, especially DHA concentrations. Reactive oxygen species attack the double bonds of polyunsaturated fatty acids and initiate chain reactions, leading to lipid peroxide formation (measured as MDA concentrations). Under the condition of antioxidant deficiency, which is the case in preeclampsia, increased peroxidative reactions further promote the decomposition of polyunsaturated fatty acids. In our earlier study on preeclamptic women, ${ }^{26}$ we reported increased oxidative stress leading to impaired essential polyunsaturated fatty acid levels as one of the key factors involved in the development of preeclampsia. Taken together, these findings on the altered levels of MDA may be relevant.

Long chain polyunsaturated fatty acids are distributed to every cell in the body where they are involved in a number of physiological processes, including the regulation of cardiovascular, immune, hormonal, metabolic, neuronal and visual functions. At the cellular level, 
Table 2 Associations between maternal VEGF, PIGF and sFIt-1 levels and birth outcome

\begin{tabular}{|c|c|c|c|c|c|c|}
\hline & \multicolumn{3}{|c|}{ Normotensive women } & \multicolumn{3}{|c|}{ Preeclamptic women } \\
\hline & $n$ & r & $P$ & $n$ & r & $P$ \\
\hline \multicolumn{7}{|l|}{ Plasma VEGF $\left(p g \mathrm{ml}^{-1}\right)$} \\
\hline Baby weight (kg) & 59 & -0.100 & 0.481 & 58 & -0.089 & 0.529 \\
\hline Baby length $(\mathrm{cm})$ & 59 & 0.043 & 0.765 & 58 & 0.029 & 0.839 \\
\hline Head circumference $(\mathrm{cm})$ & 59 & 0.019 & 0.894 & 58 & -0.081 & 0.564 \\
\hline Chest circumference $(\mathrm{cm})$ & 59 & 0.082 & 0.569 & 58 & -0.069 & 0.625 \\
\hline \multicolumn{7}{|l|}{ Plasma PIGF (pg m/-1) } \\
\hline Baby weight (kg) & 31 & 0.220 & 0.240 & 25 & 0.016 & 0.939 \\
\hline Baby length (cm) & 31 & 0.010 & 0.958 & 25 & -0.436 & $0.026^{*}$ \\
\hline Head circumference $(\mathrm{cm})$ & 31 & 0.245 & 0.193 & 25 & 0.166 & 0.416 \\
\hline Chest circumference $(\mathrm{cm})$ & 31 & 0.255 & 0.175 & 25 & -0.013 & 0.950 \\
\hline \multicolumn{7}{|l|}{ Plasma sFlt-1 ( $\left.\mathrm{pg} \mathrm{m}^{-1}\right)$} \\
\hline Baby weight (kg) & 44 & 0.140 & 0.409 & 37 & -0.547 & $0.001^{* *}$ \\
\hline Baby length (cm) & 44 & 0.049 & 0.775 & 37 & 0.075 & 0.672 \\
\hline Head circumference $(\mathrm{cm})$ & 44 & 0.188 & 0.266 & 37 & -0.472 & $0.005^{* *}$ \\
\hline Chest circumference $(\mathrm{cm})$ & 44 & 0.023 & 0.892 & 37 & -0.375 & $0.032 *$ \\
\hline \multicolumn{7}{|l|}{ Plasma sFIt-1/PIGF } \\
\hline Baby weight (kg) & 31 & -0.010 & 0.962 & 25 & -0.399 & 0.076 \\
\hline Baby length $(\mathrm{cm})$ & 31 & -0.194 & 0.363 & 25 & 0.046 & 0.884 \\
\hline Head circumference $(\mathrm{cm})$ & 31 & -0.180 & 0.400 & 25 & -0.613 & $0.003^{* *}$ \\
\hline Chest circumference $(\mathrm{cm})$ & 31 & -0.225 & 0.290 & 25 & -0.297 & 0.192 \\
\hline
\end{tabular}

Abbreviations: VEGF, vascular endothelial growth factor; PIGF, placental growth factor; sFlt-1, soluble fms-like tyrosine kinase-1.

${ }^{*} P<0.05 ;{ }^{* *} P<0.01$

Table 3 Associations between cord VEGF and sFIt-1 levels and birth outcome

\begin{tabular}{|c|c|c|c|c|c|c|}
\hline & \multicolumn{3}{|c|}{ Normotensive women } & \multicolumn{3}{|c|}{ Preeclamptic women } \\
\hline & $\mathrm{n}$ & r & $\mathrm{P}$ & $\mathrm{n}$ & r & $\mathrm{P}$ \\
\hline \multicolumn{7}{|l|}{ Plasma VEGF $\left(p g \mathrm{ml}^{-1}\right)$} \\
\hline Baby weight (kg) & 51 & -0.238 & 0.120 & 35 & -0.101 & 0.529 \\
\hline Baby length (cm) & 51 & 0.072 & 0.644 & 35 & 0.120 & 0.839 \\
\hline Head circumference $(\mathrm{cm})$ & 51 & 0.011 & 0.944 & 35 & -0.503 & 0.564 \\
\hline Chest circumference $(\mathrm{cm})$ & 51 & 0.035 & 0.820 & 35 & -0.166 & 0.625 \\
\hline \multicolumn{7}{|l|}{ Plasma sFlt-1 $\left(\mathrm{pg} \mathrm{m}^{-1}\right)$} \\
\hline Baby weight (kg) & 32 & -0.364 & $0.034 *$ & 28 & -0.027 & 0.894 \\
\hline Baby length (cm) & 32 & -0.202 & 0.252 & 28 & 0.173 & 0.378 \\
\hline Head circumference $(\mathrm{cm})$ & 32 & -0.512 & $0.002 * *$ & 28 & -0.027 & 0.892 \\
\hline Chest circumference $(\mathrm{cm})$ & 32 & -0.491 & $0.003 * *$ & 28 & -0.025 & 0.901 \\
\hline
\end{tabular}

Abbreviations: VEGF, vascular endothelial growth factor; sFlt-1, soluble fms-like tyrosine kinase-1.

${ }^{*} P<0.05 ; * * P<0.01$

these effects are mediated by changes in the structure of membrane phospholipids through interference with eicosanoid intracellular signaling and the regulation of gene expression. ${ }^{57}$ Our previous studies in preeclampsia suggest that increased oxidative stress leads to reduced maternal and cord plasma long chain polyunsaturated fatty acids, especially DHA levels, in the preeclamptic group, ${ }^{26,30}$ highlight the importance of maternal long chain polyunsaturated fatty acid status on the development of the fetus. ${ }^{58}$ Alterations in fatty acid composition in the tissue can affect tissue function by modifying membrane fluidity or membrane thickness, changing properties of the lipid phase, specifically interacting with membrane active proteins, or altering the balance of synthesized eicosanoids. ${ }^{59,60}$ The developmental processes in the placenta are mediated by VEGF and PlGF, ${ }^{61-63}$ suggesting that reduced placental membrane fluidity may lead to an imbalance in the regulation of the function of angiogenic factors.

In this study, maternal sFlt-1 levels were negatively associated with baby weight, head and chest circumference in the preeclamptic group. There are very few studies that have examined the association of maternal and cord sFlt- 1 with birth outcome. Tsao et al. ${ }^{46}$ reported a negative association of cord sFlt-1 with baby weight. However, a recent study reported that higher early pregnancy levels of sFlt-1 and PlGF were associated with a decreased risk of adverse perinatal outcomes. ${ }^{16}$ It has been suggested that undisturbed development and growth of the fetus depend on adequate vascular development in the feto-maternal unit, ${ }^{64}$ especially the placenta. Further studies need to examine the association of placental fatty acids with the expression of angiogenic factors, and this may open new avenues to improve fetal outcomes.

In conclusion, our data on altered angiogenic factors and the association of increased sFlt-1 with increased levels of the oxidative stress marker (MDA) and decreased levels of DHA suggest a causal relationship in preeclamptic women. Furthermore, these parameters are associated with adverse fetal birth outcomes in preeclampsia.

1 Fisher SJ, Roberts JM. Defects in placentation and placental perfusion. In: Lindheimer MD, Roberts JM. Cunningham FG, Appleton and Lange (eds). Chelsey's Hypertensive Disorders in Pregnancy 2nd (edn) 1999, 377-394.

2 WHO 2004, Bethesda, MD Global Burden of Disease for the Year 2001 by World Bank Region, for Use in Disease Control Priorities in Developing Countries, National Institutes of Health: WHO. Make every mother and child count. In: World Health Report 2005. World Health Organization: WHO: Geneva.

3 Maynard SE, Moore Simas TA, Solitro MJ, Rajan A, Crawford S, Soderland P, Meyer BA. Circulating angiogenic factors in singleton vs multiple-gestation pregnancies. $\mathrm{Am} \mathrm{J}$ Obstet Gynecol 2008; 198: 201-207.

4 Karumanchi SA, Bdolah Y. Hypoxia and sFlt-1 in preeclampsia: the 'chicken-and-egg' question. Endocrinology 2004; 145: 4838-4845.

5 Ye YH, Liu L, Zhan Y, Peng W. Predictive value of serum soluble fms-like tyrosine kinase 1 concentration in preeclampsia at second trimester. Zhonghua Fu Chan Ke Za Zhi 2006; 41: 433-435.

6 Maynard SE, Min JY, Merchan J, Lim KH, Li J, Mondal S, Libermann TA, Morgan JP, Sellke FW, Stillman IE, Epstein FH, Sukhatme VP, Karumanchi SA. Excess placental soluble fms-like tyrosine kinase 1 (sFlt1) may contribute to endothelial dysfunction, hypertension, and proteinuria in preeclampsia. J Clin Invest 2003; 111: 649-658.

7 Ahmad S, Ahmed A. Elevated placental soluble vascular endothelial growth factor receptor-1 inhibit angiogenesis in preeclampsia. Circ Res 2004; 95: 884-891.

8 Lee ES, Oh MJ, Jung JW, Lim JE, Seol HJ, Lee KJ, Kim HJ. The levels of circulating vascular endothelial growth factor and soluble Flt-1 in pregnancies complicated by preeclampsia. J Korean Med Sci 2007; 22: 94-98.

9 Laskowska M, Laskowska K, Leszczyńska-Gorzelak B, Oleszczuk J. Are the maternal and umbilical VEGF-A and SVEGF-R1 altered in pregnancies complicated by preeclampsia with or without intrauterine foetal growth retardation? Preliminary communication. Med Wieku Rozwoj 2008; 12: 499-506.

10 Baker PN, Krasnow J, Roberts JM, Yeo KT. Elevated serum levels of vascular endothelial factor in patients with preeclampsia. Obstet Gynecol 1995; 86: 815-821.

11 Shaarawy M, Al-Sokkary F, Sheba M, Wahba O, Kandil HO, Abdel-Mohsen I. Angiogenin and vascular endothelial growth factor in pregnancies complicated by preeclampsia. Int J Gynaecol Obstet 2005; 88: 112-117.

12 Levine RJ, Maynard SE, Qian C, Lim KH, England LJ, Yu KF, Schisterman EF, Thadhani R, Sachs BP, Epstein FH, Sibai BM, Sukhatme VP, Karumanchi SA. Circulating angiogenic factors and the risk of preeclampsia. N Engl J Med 2004; 350: 672-683.

13 Levine RJ, Lam C, Qian C, Yu KF, Maynard SE, Sachs BP, Sibai BM, Epstein FH, Romero R, Thadhani R, Karumanchi SA, CPEP Study Group. Soluble endoglin and other circulating antiangiogenic factors in preeclampsia. N Engl J Med 2006; 355: 992-1005.

14 Wikström AK, Larsson A, Eriksson UJ, Nash P, Nordén-Lindeberg S, Olovsson M. Placental growth factor and soluble FMS-like tyrosine kinase-1 in earlyonset and lateonset preeclampsia. Obstet Gynecol 2007; 109: 1368-1374. 
15 Schlembach D, Wallner W, Sengenberger R, Stiegler E, Mörtl M, Beckmann MW, Lung $\mathrm{U}$. Angiogenic growth factor levels in maternal and fetal blood: correlation with Doppler ultrasound parameters in pregnancies complicated by pre-eclampsia and intrauterine growth restriction. Ultrasound Obstet Gynecol 2007; 29: 407-413.

16 Smith GC, Crossley JA, Aitken DA, Jenkins N, Lyall F, Cameron A. Circulating angiogenic factors in early pregnancy and the risk of preeclampsia, intrauterine growth restriction, spontaneous preterm birth, and stillbirth. Obstet Gynecol 2007; 109. 1316-1324.

17 Rajakumar A, Powers RW, Hubel CA, Shibata E, von Versen-Höynck F, Plymire D, Jeyabalan A. Novel soluble Flt11 isoforms in plasma and cultured placental explants from normotensive pregnant and preeclamptic women. Placenta 2009; 30: 25-34.

18 Ahmed A, Dunk C, Ahmad S, Khaliq A. Regulation of placental vascular endothelial growth factor (VEGF) and placenta growth factor (PIGF) and soluble Flt-1 by oxygen-a review. Placenta 2000; 21: S16-S24.

19 Kendall RL, Thomas KA. Inhibition of vascular endothelial cell growth factor activity by an endogenously encoded soluble receptor. Proc Natl Acad Sci USA 1993; 90: 10705-10709.

20 Steinberg G, Khankin EV, Karumanchi AS. Angiogenic factors and preeclampsia. Thrombosis Res 2009; 123: S93-S99.

21 Kim SY, Ryu HM, Yang JH, Kim MY, Han JY, Kim JO, Chung JH, Park SY, Lee MH, Kim DJ. Increased sFIt-1 to PIGF ratio in women who subsequently develop preeclampsia. J Korean Med Sci 2007; 22: 873-877.

22 Muttukrishna S, Suri S, Groome N, Jauniaux E. Relationships between TGF beta proteins and oxygen concentrations inside the first trimester human gestational sac: PLoS One. 2008; 3: e2302.

23 Redman CW, Sargent IL. Placental stress and pre-eclampsia: a revised view. Placenta 2009; 30: S38-S42.

24 Wang A, Rana S, Karumanchi SA. Preeclampsia: the role of angiogenic factors in its pathogenesis. Physiology (Bethesda) 2009; 24: 147-158.

25 Bridges JP, Gilbert JS, Colson D, Gilbert SA, Dukes MP, Ryan MJ, Granger JP. Oxidative stress contributes to soluble Fms-like tyrosine kinase-1 induced vascular dysfunction in pregnant rats. Am J hyp 2009; 22: 564-568.

26 Mehendale S, Kilari A, Dangat K, Taralekar V, Mahadik S, Joshi S. Fatty acids, antioxidants, and oxidative stress in pre-eclampsia. Int J Gynaecol Obstet 2008, 100: 234-238.

27 Gopalan C, Rama Sastri BV, Balasubramanian SC. Nutritive Value of Indian Books. National Institute of Nutrition, Indian Council of Medical Research: Hyderabad, 1996.

28 Manku MS, Horrobin DF, Huang S, Morse N. Fatty acids in plasma and red cell membranes. Lipids 1983; 18: 906-908.

29 Kilari A, Mehendale S, Dangat K, Yadav H, Kulakarni A, Dhobale M, Taralekar V, Joshi S. Long chain polyunsaturated fatty acids in mothers and term babies. J Perinatal Med 2009; 37: 513-518.

30 Dangat K, Mehendale S, Yadav H, Kilari A, Kulkarni A, Taralekar V, Joshi S. Long chain polyunsaturated fatty acid composition of breast milk in pre-eclamptic mothers. Neonatology 2010; 97: 190-194.

31 Kwon JY, Maen YS, Kwon YG, Kim YH, Kang MH, Park YW. Endothelial progenitor cells in umbilical cord blood in severe preeclampsia. Gynecol Obstet Invest 2007; 64: 103-108.

32 Schmidt M, Dogan C, Birdir C, Callies R, Kuhn U, Gellhaus A, Janetzko A, Kimmig R, Kasimir-Bauer S. Altered angiogenesis in preeclampsia: evaluation of a new test system for measuring placental growth factor. Clin Chem Lab Med 2007; 45: 1504-1510.

33 Qazi U, Lam C, Karumanchi SA, Petri M. Soluble Fms-like tyrosine kinase associated with preeclampsia in pregnancy in systemic lupus erythematosus. J Rheumatol 2008 35: 631-634.

34 Chedraui P, Lockwood CJ, Schatz F, Buchwalder LF, Schwager G, Guerrero C, Escobar GS, Hidalgo L. Increased plasma soluble fms-like tyrosine kinase 1 and endoglin levels in pregnancies complicated with preeclampsia. J Matern Fetal Neonatal Med 2009; 6: 1-6.

35 Reddy A, Suri S, Sargent IL, Redman CW, Muttukrishna S. Maternal circulating levels of activin $A$, inhibin $A, s F I t-1$ and endoglin at parturition in normal pregnancy and preeclampsia. PLoS One 2009; 4: e4453.

36 Woolcock J, Hennessy A, Xu B, Thornton C, Tooher J, Makris A, Ogle R. Soluble Flt-1 as a diagnostic marker of pre-eclampsia. Aust N Z J Obstet Gynaecol 2008; 48: 64-70.

37 Munaut C, Lorquet S, Pequeux C, Blacher S, Berndt S, Frankenne F, Foidart J. Hypoxia is responsible for soluble vascular endothelial growth factor receptor-1 (VEGFR-1) but not for soluble endoglin induction in villous trophoblast. Hum Reprod 2008; 23: 1407-1415.

38 Chaiworapongsa T, Espinoza J, Gotsch F, Kim Y, Kim G, Goncalves L, Edwin S, Kusanovic JP, Erez O, Than NG, Hassan SS, Romero R. The maternal plasma soluble vascular endothelial growth factor receptor-1 concentration is elevated in SGA and the magnitude of the increase relates to Doppler abnormalities in the maternal and fetal circulation. J Matern Fetal Neonatal Med 2008; 21: 25-40.

39 Savvidou M, Yu CK, Harland LC, Hingorani AD, Nicolaides KH. Maternal serum concentration of soluble fms-like tyrosine kinase 1 and vascular endothelial growth factor in women with abnormal uterine artery Doppler and in those with fetal growth restriction. Am J Obstet Gynecol 2006; 195: 1668-1673.

40 Rajakumar A, Michael HM, Rajakumar PA, Shibata E, Hubel CA, Karumanchi SA, Thadhani R, Wolf M, Harger G, Markovic N. Extra-placental expression of vascular endothelial growth factor receptor-1, (FIt-1) and soluble Flt-1 (sFlt-1), by peripheral blood mononuclear cells (PBMCs) in normotensive and preeclamptic pregnant women. Placenta 2005; 26: 563-573.

41 McKeeman GC, Ardill JE, Caldwell CM, Hunter AJ, McClure N. Soluble vascular endothelial growth factor receptor-1 (sFlt-1) is increased throughout gestation in patients who have preeclampsia develop. Am J Obstet Gynecol 2004; 191: $1240-1246$.

42 Clark DE, Smith SK, He Y, Day KA, Licence DR, Corps AN, Lammoglia R, CharnockJones D. A vascular endothelial growth factor antagonist is produced by the human placenta and released into the maternal circulation. Biol Reprod 1998; 59. 1540-1548.

43 De Vivo A, Baviera G, Giordano D, Todarello G, Corrado F, D'anna R. Endoglin, PIGF and sFlt-1 as markers for predicting pre-eclampsia. Acta Obstet Gynecol Scand 2008; 87: 837-842.

44 Masuyama H, Segawa T, Sumida Y, Masumoto A, Inoue S, Akahori Y, Hiramatsu Y. Different profiles of circulating angiogenic factors and adipocytokines between earlyand late-onset pre-eclampsia. BJOG 2010; 117: 314-320.

45 Galazios G, Papazoglou D, Giagloglou K, Vassaras G, Koutlaki N, Maltezos E. Umbilical cord serum vascular endothelial growth factor (VEGF) levels in normal pregnancies and in pregnancies complicated by preterm delivery or pre-eclampsia. Int J Gynaecol Obstet 2004; 85: 6-11.

46 Tsao PN, Wei SC, Su YN, Chou HC, Chen CY, Hsieh WS. Excess soluble fms-like tyrosine kinase 1 and low platelet counts in premature neonates of preeclamptic mothers. Pediatrics 2005; 116: 468-472.

47 Ferrara N, Davis-Smyth T. The biology of vascular endothelial growth factor. Endocr Rev 1997; 18: 4-25.

48 Cheung CY. Vascular endothelial growth factor: possible role in fetal development and placental function. J Soc Gynecol Invest 1997; 4: 169-177.

49 Silverman WF, Krum JM, Mani N, Rosenstein JM. Vascular, glial and neuronal effects of vascular endothelial growth factor in mesencephalic explant cultures. Neuroscience 1999; 90: 1529-1541.

50 Gupta P, Ray M, Dua T, Radhakrishnan G, Kumar R, Sachdev HPS. Multimicronutrient supplementation for undernourished pregnant women and the birth size of their offspring. A double-blind, randomized, placebo-controlled trial. Arch Pediatr Adolescent Med 2007; 161: 58-64.

51 Brownbill P, Mills T, Soydemir D, Sibley C. Vasoactivity to and endogenous release of vascular endothelial growth factor in the in vitro perfused human placental lobule from pregnancies complicated by preeclampsia. Placenta 2008; 29: 950-955.

52 Malamitsi-Puchner A, Tziotis J, Protonotariou E, Sarandakou A, Creatsas G. Angiogenic factors in the perinatal period: diversity in biological functions reflected in their serum concentrations soon after birth. Ann N Y Acad Sci 2000; 900: 169-173.

53 Ali KZ, Burton GJ, Khalid ME, Moosa R, Abd-alla S. Concentrations of free vascular endothelial growth factor in the maternal and foetal circulations during pregnancy: A cross-sectional study. J Maternal-Fetal Neonatal Med 2010 (in press).

54 Abid M, Schoots I, Spokes K, Wu S, Mawhinney C, Aird W. Vascular endothelial growth factor-mediated induction of manganese superoxide dismutase occurs through redox-dependent regulation of forkhead and lêB/NF-êB. J Biol Chem 2004; 279: $44030-44038$.

55 Gonzalez-Pacheco FR, Deudero JJP, Castellanos MC, Castilla MA, varez-Arroyo MV, Yague S, Caramelo C. Mechanisms of endothelial response to oxidative aggression: protective role of autologous VEGF and induction of VEGFR2 by H2O2. Am J Physiol Heart Circ Physiol 2006; 291: H1395-H1401.

56 Hood JD, Meininger CJ, Ziche M, Granger HJ. VEGF upregulates ecNOS message, protein, and NO production in human endothelial cells. Am J Physiol 1998; 274: 1054-1058.

57 Porta N, Auvin S. Polyunsaturated fatty acids: anticonvulsive effects and underlying mechanisms. Med Sci (Paris) 2009; 25: 51-56.

58 Muskiet FA, van Goor SA, Kuipers RS, Velzing-Aarts FV, Smit EN, Bouwstra H, DijckBrouwer DA, Boersma ER, Hadders-Algra M. Long-chain polyunsaturated fatty acids in maternal and infant nutrition. Prostaglandins Leukot Essent Fatty Acids 2006; 75: $135-144$.

59 Stubbs CD, Smith AD. Essential fatty acids in membrane: physical properties and function. Biochem Soc Trans 1993; 18: 779-780.

60 Zurier RB. Fatty acids, inflammation and immune responses. Prostaglandins Leuko Essent Fatty Acids 1993; 48: 57-62.

61 Risau W. Mechanisms of angiogenesis. Nature 1997; 386: 671-674.

62 Yancopoulos GD, Klagsbrun M, Folkman J. Vasculogenesis, angiogenesis, and growth factors: ephrins enter the fray at the border. Cell 1998; 93: 661-664.

63 Sibai B, Dekker G, Kupferminc M. Pre-eclampsia. Lancet 2005; 365: 785-799.

64 Herr F, Baal N, Zygmunt M. Studies of placental vasculogenesis: a way to understand pregnancy pathology? Z Geburtshilfe Neonatol 2009; 213: 96-100. 